\title{
Challenges for using organizational climate tools for measuring teacher job satisfaction
}

\author{
Yahya Don ${ }^{1}$, Mohd Faiz Mohd Yaakob ${ }^{2}$, Wan Rozimi WanHanafi ${ }^{3}$, Mat Rahimi Yusof ${ }^{4}$, Muhamad \\ Dzahir Kasa $^{5}$, Mohd Sofian Omar-Fauzee ${ }^{6}$, Hareesol Khun In-Keeree ${ }^{7}$ \\ 1,2,3,4,5,6 School of Education, Universiti Utara Malaysia, Malaysia \\ ${ }^{7}$ School of Liberal Arts, Walailak University, Thailand
}

\begin{tabular}{l} 
Article Info \\
\hline Article history: \\
Received Sep 29, 2020 \\
Revised Mar 28, 2021 \\
Accepted Apr 13, 2021 \\
\hline
\end{tabular}

\section{Keywords:}

Organizational climate Primary school teachers School learning resources Teacher job satisfaction

\begin{abstract}
The organizational environment includes not only the landscape of a school, but also the components of school learning resources, student relations, communication-collaboration, decision-making and instructional innovation. According to the ministry of education, many schools do not have the new facilities needed for successful teaching and learning to meet the potential needs of the workforce. Further investigation is still needed as to how these elements make teachers enjoy a working environment, particularly in Kedah, Malaysia. It would also help the State department of education to address unresolved school issues. The aimed of this research is to examine primary school teachers' understanding of their teacher satisfaction and organizational environment. The design of this study was mix-method consisting of a survey (quantitative approach) and a semi-structured interview (qualitative approach). A sample of 220 teachers in 23 primary schools in Alor Janggus, Kedah participated in this study. On the other hand, a total of 20 teachers were interviewed to identify factors that would lead to teacher satisfaction at work and an organizational environment. The content analysis was used to identify the themes that emerged from the semi-structure interview. The themes emerged from the semi-structure interviews are student relationships, decision-making, school infrastructure, teamwork and educational creativity. Suggestions for future research are discussed in more detail.
\end{abstract}

This is an open access article under the CC BY-SA license.

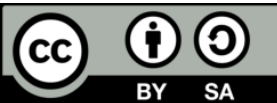

\section{Corresponding Author: \\ Mohd Faiz Mohd Yaakob \\ School of Education and Modern Languages \\ Universiti Utara Malaysia \\ 06010 Bukit Kayu Hitam, Malaysia \\ Email: mohdfaizmohdyaakob@gmail.com}

\section{INTRODUCTION}

Education is as an agent of change towards the formation of the intended projection which requires education reform to meet the obligation with the compulsive detailed of information to achieve the goal of achieving the vision and mission towards academic excellence [1]. The designated projection is a step towards developing a comprehensive national education development to achieve the quality, educational excellence and physical development of the educational institution as stated in the Malaysian Development Plan 20132025 blueprint [2]-[4]. To ensure the country's educational goals are achieved, it is argued that teachers should play an important role in education children through their commitment, motivation, and teaching competencies. [5]. In addition to the teacher factor, the school environment and school climate factors are also a necessary feature as they also influence the behavior of teachers and school leadership in shaping the organization's climate excellence. The school climate is an internal environment that includes the physical, infrastructural, 
instructional, and emotional aspects of teachers that create a peaceful, comfortable and enjoyable environment [6]. These factors contribute to the achievement of the school as it is closely related to the conducive and comfortable school environment. This feature is able to distinguish one organization from another, a school that has a good organizational climate will excel in its academic performance compared to a school that does not care about it [5].

In creating a conducive school climate, it is imperative for the school leadership to acquire prediction, insight and creativity to plan the right transformation in order to create not only a comfortable school environment, but to make it a fun place for teachers to work. Therefore, schools need leader who can create transformations in transforming the school culture and teaching profession more effectively into excellence. The finding supported by Fei and Han [7] who state that a good school climate can be considered a conducive environment in a school. This comfortable condition will indirectly affect the teachers and students in producing a fun learning culture which also will influence their positive attitude towards the school. Moreover, the school's climate has been directly related to the satisfaction level of teachers' work [8]. This can be explained that teachers who acquire high level of teaching and working satisfaction in school will also give their helping hand and commitment in teaching. Thus, this is to ensure students' academic achievement is improving. Likewise, Valdez, et al. [9] also found that the organization's climate has a direct relationship with job satisfaction. This also means that the school with conducive working environment will helps to increasing the level of teachers' job satisfaction.

Alongside that, the satisfaction of the teacher's work is also closely related to participation in decision making, high autonomy in schools, environmental conditions, working relationship, and progress in students' achievement [10]. This means that besides the teaching factors, other factors proposed by Zamani and Karimi [10] should also be given consideration by the school leaders to ensure that their teachers remain committed in carrying out their duties in the school. Alternatively, the positive relationship is important because the teachers who are satisfied with their teaching jobs and school climate often become the most committed to achieving the goals and targets that had been set-up by the authority. This is because the school's performance is highly dependent on its employees and school climate. The school with high positive climate obviously will able to achieve their school mission and vision easily, while those with negative climate will be facing a more demanding challenges to obtain the school goals [11]. In addition, the findings of Mukhtar [12] have also found that a good organizational climate can help influence employee behavior and thus enhance employee performance.

As such, schools require a leader who is able to create a positive school culture in enhancing teacher commitment to teaching [13]. Therefore, a comprehensive relationship between the entire work force of a school whether administrators with teachers, teachers with teachers, teachers with students and students with students needs to be established as a sound school culture [6]. Furthermore, Bai, et al. [5] state that the school organization climate is a very important factor in helping a school succeed with excellent academic achievement. To realize this, school leader is the most important human resource in leading an organization and they also play a role in creating a harmonious climate to the job satisfaction of their teachers. To do this, organizational leaders must be responsible for building positive and motivating employees [9]. Thus, it clearly shows that school achievement is highly influenced by a conducive and positive school climate. Hence, this clearly shows that the school's performance is highly influenced by a conducive and positive school climate.

\section{RESEARCH PROBLEM}

Organizational climate is closely related to teacher job satisfaction in schools, schools where teachers and staff do not enjoy their working conditions will resulted in unfulfilled school vision and mission. Therefore, teacher job satisfaction is critical to improving organizational performance. According to Valdez, et al. [9], each organization has an organizational climate that largely influences a person's personality. This shows that organizational climate contributes to organizational success and employee satisfaction. A study conducted by Wynn [13] also found that organizational climate and job satisfaction play an important role in organizational success. However, many school organizations still lacking of the elements to create a conducive school climate that fails to influence teacher job satisfaction. In the study by Hassan and Wahab [14], they found that teacher satisfaction was at a moderate level due to the negative organizational climate. This non-conducive school environment has caused teachers to feel less comfortable in their teaching jobs. Among the reasons of being uncomfortable is because the school has a shortage of resources that should not have taken place in their work place. In addition, a report in the Malaysian Education Development Plan 2013-2025 blueprint also revealed that despite significant improvements, the ministry was aware that significant gaps still exist in the development of school infrastructure [4]. Many schools do not have the latest facilities that are essential for effective teaching and learning to meet future workforce needs. The 2013-2025 Malaysian Education Development Plan's blueprint report shows that about 2,700 schools do not have computer labs and 2,000

Int J Eval \& Res Educ, Vol. 10, No. 2, June 2021: 465 - 475 
schools do not have science labs [4]. Because of this issue, there is a need of this research to examine the level of organizational climate and teacher job satisfaction in of Alor Janggus area, Kedah.

Moreover, Hamdan [15] have also found that one of the factors that the Ministry of Education has yet to fully grasp is the teaching effectiveness among teachers and unable to provide a comfortable and conducive organizational climate to all schools. This statement is also supported by Kapa and Gimbert [16] which states the dissatisfaction of teachers' work in most schools due to the unenjoyable workplace conditions. This clearly shows that headmaster should focus on teacher job satisfaction which was inter-related with the pleasant situation at the work place [17], [18]. Further, the crucial problem occurred is due to the enthusiasm of the headmasters who only wanted to see the school academic achievement by disregarding teacher job satisfaction [19]. Therefore, headmasters need to play a role in balancing between a positive organization's climate and the satisfaction of teachers' work. This suggestion is in line with the Ministry of Education plan, which requires the teacher to create a sound practice, climate and healthy school cultured. This shows that indeed the school's climate is an aspect that needs to be emphasized in all educational institutions, especially in schools because of its positive contribution to teacher working satisfaction. The problems still exist due to the lack of research on the factors of teacher dissatisfaction due to the climate of school organization especially for schools in Kedah, Malaysia. Conversely, very few studies were implemented in the Alor Jangus area, Kedah on how the school's climate contribute to the teacher job satisfaction. With this study, it will help the Kedah state Education Department to formulate a special program in formulating a special program to ensure the students' academic achievement improved. The comprehensive planning of the Malaysian Education Development Plan 20132025, which is in the 7th years, says that teachers and school leaders are the most important catalyst to enhance student success. This will also indirectly help to improve the overall school performance. Therefore, this mixmethodology study will examine the school's climate and teacher job satisfaction in Alor Janggus, Kedah.

\section{RESEARCH METHOD}

The data for this study were obtained using two methodologies; that are quantitative and qualitative approaches. In order to explain the methodology of the two methods they are separated into different subthemes.

\subsection{Quantitative studies \\ 3.1.1. Samples}

Quantitative approach employed a cross-sectional survey method with standardized questionnaire as a survey instrument. This study involved primary schools in Alor Janggus area, Kedah, Malaysia. In Alor Jangus, there were 23 primary schools with a population of 516 teachers. According to the sampling method proposed by Krejcie and Morgan [20], when the population size is within the range of 516, the sample size is 220. Therefore, the researchers decided to use 220 samples in this study.

\subsubsection{Study instruments}

In this study, the researcher has prepared a questionnaire containing three sections, part A for teacher demographics, which is used to measure the personal information of the teacher. Part B is used to obtain information about the school organization climate containing 21 items. The School Level Environment Questionnaires (SLEQ) instruments developed by Johnsons, et al. [21] is used to measure organizational climate. The five organizational climate dimensions and internal consistency (alpha Cronbach) which are as; communication-collaboration (0.84), student relationship (0.82), school resource (0.85), decision making (0.81) and instructional innovation dimension (0.87). Whereas, Section C consisting The Teacher Job Satisfaction Questionnaires (TJSQ) that is developed by Lester [22] to measure teacher satisfaction. The instrument of teacher satisfaction consists of 66 items. The reliability of the TJSQ is with the value of Alpha Cronbach of 0.88. All questions use a 5-point Likert scale from 1-Strongly Disagree to 5-Strongly Agree.

\subsubsection{Research procedures}

Prior to conducting the actual study, the researcher conducted a pilot study on 30 teachers in one of the schools outside Alor Janggus area. These respondents will not be involved in the actual study. The reason of conducting the pilot study is to identify the reliability of the instruments and to get the feedback from the respondents if any of the questions are difficult to understand, confusing, and inappropriate. With the feedback, the researchers will be tested again and modify before the real study is conducted. The Cronbach alpha score for all the dimensions of organizational climate is between $0.80-0.93$; whereas the job satisfaction is 0.87 .

Moreover, in order to initiating the data collection process, researchers will seek permission from the ministry of education; the education policy research and planning division (EPRD) in advance of the study to be undertaken. The online application with the proposal and questionnaire has to be submitted to EPRD to get 
the approval of conducting research to the school. In about a week, an approval letter from EPRD received through researcher personal email address. To comply with the rules, researchers will submit formal requests to the Kedah State Education Department (KSED). After receiving the letter from the Kedah state Education Department, the researcher will individually seek the approval to the headmaster to collect data from the teachers teaching in the schools that are selected earlier through stratified random sampling. The headmasters have appointed a senior assistant teacher as the coordinator who will submit the questionnaire to the teachers involved. After one week, the form will be taken by the researcher through the senior assistant for analysis. The form is checked in advance to ensure that the form is complete and all questions have been answered with only one answer selected. The teachers had returned the completed 220 questionnaires to the senior assistance for researcher to process the analysis of data.

\subsection{Qualitative studies}

\subsubsection{Sample of the study}

The researchers used focused on the dimensions identified by the previous literature review. There were 10 of the participating teachers who involved in the first study (quantitative survey methodology) agreed to be interviewed. The respondents were requested to sign an informed consent letter which agreed that the interviewed would be taped recorded by the researchers. Interviews were administered at the school as agreed by both parties.

\subsubsection{Procedure of the study}

Of the 220 primary school teachers participated in survey study, a sample of 20 primary school teachers were chosen to participate in the interview sessions. The interview session was conducted during the first week following the completion of the survey questions. The interviews were conducted by the researchers and lasted between 30 and 40 minutes. Follow-up interviews were conducted if clarification was required. Interviews were granted from all the participants and the researcher ensured that the confidentiality of primary school teachers was maintained. The data is transcribed from the audio tapes of each interview. In this study, the researchers developed interview questions based on the results of previous literature. They challenge the organizational atmosphere and job satisfaction of the school community as: 1) Do you believe, or do you think you're happy with your work right now? Why or why not? 2) What are your thoughts about the relationship of teachers and students in your school? Why is this happening? 3) What do you think about teaching creativity in relation to your school's organizational environment? What's the reason for that? 4) What is your response to the organizational environment in the school decision-making process? What's the reason for that? 5) How does the relationship between administrators, teachers and students respond to the organizational climate of your school? Why is it that way? 6) What are your thoughts on school tools and learning programs for your school's organizational environment? Why is that happening? 7) What are your general views on teacher satisfaction and the organizational environment of your school? Why is this happening?

These questions were used to gather information about teachers' understanding of their own feelings and experiences while at school and how these perceptions have been affected. Further questions were answered only as a follow-up to the teacher's answers or explanation. Before it was included in the actual analysis, two teachers tested the questions. Interviews were examined individually as well as collectively using the theory-based approach. A comprehensive line-by-line analysis was also used to create initial categories and suggested relationships between different categories. Text analysis means that the data obtained using the coding method are carefully analyzed and interpreted in detail. Free coding was initially used. The data were separated by questions and then related events grouped together and assigned a single conceptual mark or category. The data has been compared. As the questions focused on the previous dimensions of the research, some of the answers were based on the previous literature review of the thematic themes mentioned earlier. Selective coding processes have been used to incorporate categories in order to create a general structure with subsequent topics.

\section{RESULTS AND DISCUSSION}

The following section will have discussed the results of the quantitative research with the quotations which was answered by the respondents during the interview sessions. The first part of this session will include the respondents' profile, the level of organizational climate and job satisfaction of the teachers, the t-test and ANOVA of the organizational climate and job satisfaction, and the correlations between the organizational climate and job satisfactions that perceived by the teachers. 


\subsection{Respondent's profile}

Table 1 shows the profile of the respondents which includes: gender, age, teaching experience, education and working with the current headmasters.

Table 1. The demographic profile of the respondents

\begin{tabular}{llcc}
\hline & Variables & Respondents & $\%$ \\
\hline Gender & Male & 106 & 48.2 \\
& Female & 114 & 51.8 \\
Experience & 1 to 5 year & 0 & 0 \\
& 6 to 10 year & 29 & 13.2 \\
& 11 to 15 year & 109 & 49.5 \\
& 16 year and above & 82 & 37.3 \\
\hline
\end{tabular}

\subsection{The teacher's job satisfaction and organizational climate}

Figure 1 describes the findings of the overall score of job satisfaction and organizational climate; and its dimensions student relationship, instructional innovation, decision making, collaboration and school facilities.

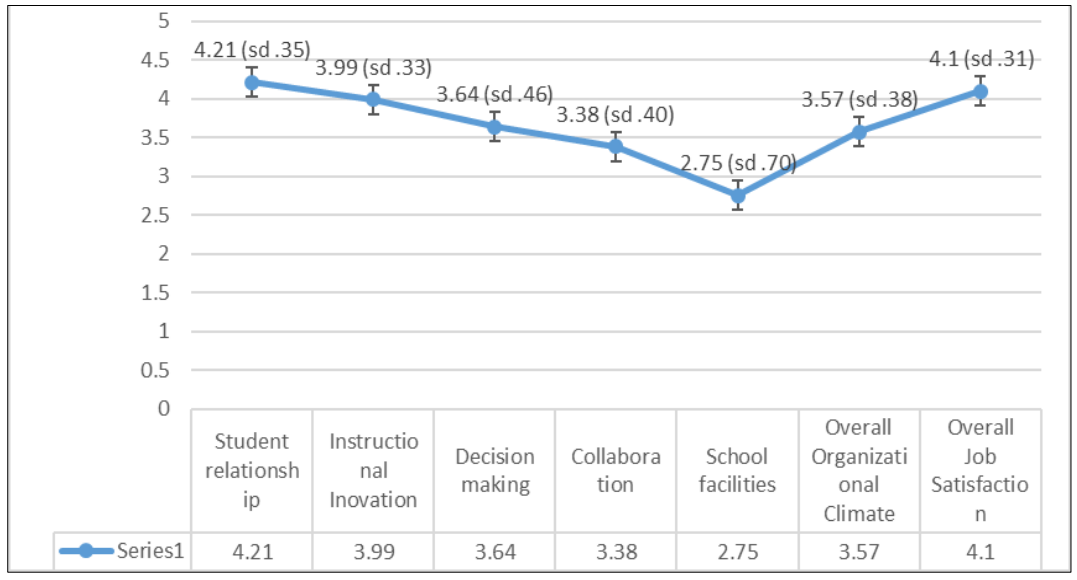

Figure 1. The mean score of job satisfaction and organizational climate

\subsubsection{The teacher job satisfaction}

According to Locke [23], work satisfaction is taken as the degree of happiness, comfort and the fulfillment of needs that a person achieves through his profession or daily work. Satisfaction or dissatisfaction with an apprenticeship can result from interaction with students, collaboration with fellow students and parents or from an episode such as an effective lesson that interacts [16]. The level of satisfying an educator is often influenced by individual histories through everyday contact with teaching; teaching interactions often form the teacher's satisfaction with his work [24]. Learning environments are also influencing the work satisfaction of the teacher and the potential of the learning [7], [14], [25].

Furthermore, working conditions, such as roles assigned to teachers, administrative support, classroom and behavior management support, relations with colleagues, quality of facilities and class sizes, are often cited as the most significant factors affecting the satisfaction of teachers at work [7], [11], [12], [17], [18]. Achieving professional anticipation and personal aspirations in the teaching profession is essential, as it is linked to more productive job performance [26]. Contrarily, dissatisfaction with teaching work leads to lower motivation and less desire to remain in the teaching profession [6].

Based on the result, the mean score of overall job satisfaction and overall score of organizational climates and its dimensions (student relationship, instructional innovation, decision making, collaboration and school facilities) showing that student relationship mean score was the highest and school facilities is the lowest. The overall mean score of teacher satisfaction is with means of 4.1 ( $\mathrm{sd}=.31)$ which was considered high that means that the teachers in the designated area perceived that their working environment is considered satisfactory. Perhaps, the head master is very supportive and willing to listen to any suggestions from the 
teachers to ensure that all teachers feel comfortable and subsequently achieve the satisfaction of teaching [27]. One of the interviewees (TA:29/4) agrees with the finding who stated that:

"The way my headmaster managed the school made me feel very welcome and appreciated at school. As a teacher, you can feel that the way he politely listens to our suggestions and opinions makes me feel like part of the administration. On the other hand, he gave us full support for how we conduct classes, and I feel very proud when I was around. This is because he's never making a bad comment to me, and he's always thinking about motivation and making me feel very comfortable with him. Perhaps his experience of being a leader for so many years has made him my ideal leader."

Adeniji, Falola, and Salau [28] support the statement and argue that the definition of work satisfaction is characterized as an agreeable or optimistic emotional condition as a result of the assessment of jobs. Therefore, school leadership and the school climate are part of the evaluation criteria. A supportive headmaster therefore allows teachers to support themselves and to enjoy working conditions [13]. Fei and Han [7] also notes that a culture of successful schooling that is decided by representatives has influenced students and teachers' evaluation of their schools and their approach to learning. The findings indicate that lecturers' satisfaction with the organizational climate is high. In terms of colleagues, current employment, members and managers, advancement and salary chancels, all lecturers have high rates of satisfaction. In addition, a study conducted by Wahab and Abdullah [27] on 300 teachers at the Johor Government Religious School looked at teacher work satisfaction in terms of leadership style, work management and teacher job satisfaction. The findings show that teachers' perceptions of leadership style and work management are at a high level with teachers' job satisfaction. Teachers are satisfied with the leadership made by the headmaster and the management he or she performs. This means, therefore, that leaders in the education sector, especially at school, should prepare themselves as a medium to inspire teachers to work comfortably.

However, there is also inconsistent findings with this study as was conducted by Kariming and Ambatong [6] on 399 teachers in Tawau, Semporna and Lahad Datu districts who have found that teacher satisfaction levels are at a moderate pace especially concerning on school resources. Teachers in the district are dissatisfied with the infrastructure available at the school which is inadequate. Poor school resources have also led to displeasure among teachers to teach because some of the teaching material they have to utilize their own money buying teaching materials. Even though, the headmaster (HTA:29/4) was very supportive but if the poor school resources will deteriorate the good working satisfaction among teachers. The following are the suggestions made by teachers to improve their level of job satisfaction:

"I have no doubt about the ability of my head master, who is very experienced and supportive of the teachers, and who has also built a good relationship with the students. He was capable of creating a good working environment between school administrations and teachers, teachers and teachers, school administrations and students, and teachers and students. Everyone seems to enjoy working in the school under his leadership. However, Ifeel that there is a space that needs to be improved to ensure that the motivation to work with my head masters is always well. Ifelt that school administration should look at the lack of school resources that should be made available to teachers, especially for good teaching and learning. Some of the facilities, the school that can't provide teachers, and the teachers themselves, have to use their own computer and other teaching materials as the teaching stuff. Although, because of the love of teaching that teachers have to buy all these things, the school should consider it a priority in the next school session to ensure that all the materials suggested that the school should be provided are ready when the time comes. By this way, I'm sure the motivation of the teacher will be sustained. This is my suggestion."

In order to maintain the satisfaction of the teacher at school, the suggestion made by the respondent above should be seen as a priority by the school authorities as well as by the ministry of education. It is important to ensure that a satisfactory level of education among primary school teachers in this school district is continually strengthened.

\subsubsection{The school organizational climate and job satisfaction}

A study by Maiti [11] has found that negative and positive attitudes can affect a number of aspects of organizational behavior in the workplace. The importance of job satisfaction in the organization, in particular in terms of employee relations, turnover, absenteeism, productivity and efficiency, has been demonstrated. In addition to numerous environmental and situational factors, such as low-quality materials, and inadequate

Int J Eval \& Res Educ, Vol. 10, No. 2, June 2021: 465 - 475 
material supply, the level of satisfaction is affected by performance [28]. However, performance in low-level jobs requiring less capacity is determined solely by job satisfaction. This is why, if employees are not satisfied, their productivity, job performance, obligations and interpersonal relationships with subordinates and managers will also suffer [29]. For example, in organizations where salary increases and promotions are not granted for recognition of work performance, employee productivity tends to decrease [30]. Many managers use incentive programs to meet the needs of employees, although research has shown that no amount of money will be spent on a sustainable level. Teachers want their career path to fulfilment. However, this public perception is influenced by both positive and negative influences. In addition, it was found to be optimistic how teachers view their roles in a school organizational system where regulations have been placed in place and implemented by both teachers and colleagues [16].

The results of the descriptive analysis have been conducted, showing that the climate of school organization among these primary school teachers are at a moderate level $(\mathrm{M}=3.57, \mathrm{SP}=0.38)$. Thus, this indicates that the school organization climate in the study area is acceptable. In this study, teachers seem contributing something positive to their respective schools. Teachers display appreciation to their school administration which have makes them feel safe and had acquired high level of job satisfactions [9]. As a result of their high job satisfactions, it can also increase their loyalty to the school. In the interest of that, Anjilus and Talip [31] agreed that a healthy and positive organizational climate is necessary to increase the level of satisfaction of teachers for the achievement of organizational goals. Thus, this means that the job satisfaction was found to be inter-related with the organizational climate. Therefore, the prominent school organizational climate will heighten teachers' job satisfaction and they will be admired and enjoyed their work [18]. Thus, this study found that job satisfaction is crucial in shaping a positive organizational climate. On the other hand, student relationship dimension $(\mathrm{M}=4.21, \mathrm{SP}=0.35)$ was the highest mean score of organizational climates. This explains that having good student relationships between teachers have created a positive and conducive school organizational climate. According to Mutiara and Sobandi [32] the school climate plays an important role in developing a healthy and positive school environment. A positive climate will elevate the valuable process of teaching and learning between teachers and students. Their research also found that the school organization climate is considered positive when it comes to features such as a productive working environment, good social relationships among school children, comfortable environment, school cleanliness and attractive layout and landscape. One of the respondents (TB:29/4) suggest that student-teacher relationship plays an important role of better school organizational climate:

"As a teacher with experience, I am proud of what the students have done to me. They make me feel like home and more valued as their instructor. Since they are children between 7 and 12 years of age, their well-being has been excellent. This student-teacher partnership has provided a successful learning atmosphere for me to teach at this school. The interaction with the students made me feel like I was here because of them."

The findings also indicate strong administration cooperation with teachers and students. Collaboration between administrators, teachers and students seems to have created a satisfactory organizational climate within the school. This will help to improve the academic achievement of the school [26]. The study found that the organizational climate showed a high average score. Thus, if the climate of school organization is high, the influence of the teacher on the school is also high. Similarly, the results of the study show that if there is a good and friendly relationship between teachers and teachers, as well as a positive relationship between administration and teachers, the climate of school organization will improve. Therefore, when the organizational climate is high, the level of satisfaction of teachers will increase. One of the respondents (TC:29/4) also mentioned the following on the positive relationship between administration-teacher and teacher-teacher collaboration:

"Personally, I feel comfortable at this school, although I've only been in school for about six months. The situation at my old job isn't as good as at job. Perhaps the atmosphere built by administrators and teachers working together to solve problems or help improve teaching resources made me feel welcome. Therefore, such cooperation should be retained to ensure teachers enjoy working in this good working environment."

This strong partnership has also been agreed by Kariming and Ambatong [6] who stated that in order to increase productivity and job satisfaction, a school must create a climate that promotes a high level of organizational climate, which is the link between all components of a school whether administrators with teachers, teachers with students and students with students. 
In addition, good cooperation between teachers has also made it possible for teachers to benefit further. They have improved their innovation in teaching in order to improve student teaching aids. On the other hand, because of the good cooperation between the administration and the teachers, the Master-in-Chief gave the teachers the opportunity to present their ideas in certain decision-making processes. This kind of recognition made the teacher feel very much appreciated. In addition, Kapa and Gimbert [16] study included responses from more than 37,000 public school teachers in more than 7,800 schools across the United States. They found that schools with a favorable environment can enhance teacher job satisfaction and also found that there is a significant relationship between teacher job satisfaction and teacher collaboration. However, the following teacher agrees (TD:29/4) with the above-mentioned teachers:

"For me, I am satisfied with the school situation that involves administration, the classroom climate, the rest room, the canteen, the library, the landscape, administration and teacher collaboration, and the relationship between teachers and teachers, as well as the relationship between teachers and students. All of the organizational climate dimension, as I said earlier, seems to have been fulfilled by my school administration. The senior and junior teachers, on the other hand, work together on computer and technology innovation for the benefit of students. In my case, it seems that younger teachers under the age of 35 appear to be very knowledgeable and highly skilled in creating innovative computer-based technology teaching and willing to help other teachers. This kind of good relationship made my school better than any other school in this area. Of course, if you have a good leader, you can create a good working environment and a good school environment for learning and teaching."

This result is also confirmed in a study conducted by Maiti [11] found a strong relationship between teachers' leadership level and job satisfaction. Principals that care for their workers will improve teacher satisfaction. Therefore, as a school leader, the headmaster/ headmistress should sustain or build a positive school environment to increase teacher job satisfaction. In addition, Aziz and Hussin [8] study of 252 teachers from nine secondary schools in the Kuala Terengganu district also found that there is a positive impact on the school climate and the level of teacher satisfaction.

On the other hand, research also shows that school resources were the lowest average score perceived by teachers. School resources include student learning facilities such as resource centers, science rooms, ICT rooms, self-access learning (SAL) rooms, music rooms and the art and visual education room [4]. As a result, teachers seem to have perceived that school resources are inadequate. This shows that although the level of job satisfaction was found to be appropriate, as suggested by the teachers, but also suggested by the teachers that, in due regard, the resources provided will improve job satisfaction along with the organizational climate and student academic achievement. Therefore, the limelight is also to ensure that the school resources is sufficiently available. Similarly, a study conducted by Hassan and Wahab [14] who examined the level of job satisfaction among 250 teachers in low-performing schools in Bangsar Zone, Kuala Lumpur. The study found that secondary school teachers in Bangsar Zone experienced moderate levels of job satisfaction due to the organizational climate is not adequate enough such teacher-student relationship of misbehaved students, inadequate school resources, and the school community area. Based on the Hassan and Wahab [14] study, the school should make sure that the school resources for teaching is tolerable enough for teachers to apply it in teaching. To justify, one of the respondents (TE:29/4) pleaded to the administration to improve her school teaching resources:

"I believe my school should have better facilities for a science laboratory, an ICT room, a self-access center and a resource room. What we have is very old, and some of the facilities are no longer working. If it doesn't work, how are we going to teach the students more appropriately? It seems that my school's teaching resources facility is always inadequate, and this has been going on for more than six months. I don't know about any other school in the vicinity, but I thought my school was lacking in teaching resources. In addition, when asked by the head mistress, she has always given the reason that the State Department of Education has not allocated the budget to our school and therefore no new facilities can be purchased without the approval of the Education Department. As you know, I am teaching at primary school, of course we need a lot of educational resources to enhance the children's interest in learning. Personally, I hope that the administration should also try to find an alternative allocation for teaching and learning purposes."

This shows that teachers are willing to wait, but if the facilities have not been repaired for more than six months, it is intolerable. The head mistress should find other alternative ways, such as through the parent-

Int J Eval \& Res Educ, Vol. 10, No. 2, June 2021: 465 - 475 
teacher of the school association, to raise money to overcome the problems. At the same time, of course, the head mistress should continue to ask the State Department of Education to replace the defective equipment. On the other hand, the lack of resources does not involve the entire population of the study. Some schools are sufficient and adequate, one teacher said, "My school doesn't have any problems with teaching resources, because our headmaster is an experienced teacher, and she knows that teaching resources should be the number one priority in school." Another teacher also said, "I know my friend school has a problem with facilities, but this doesn't happen to my school." Teachers are in dire need of sufficient school resources to facilitate learning and facilitate a student-oriented approach. According to Kariming and Ambatong [6], organizations and institutions need resources to produce better output. In addition to the positive environment, school resource facilities should also be seriously neglected by the administration to ensure that the level of satisfaction of teachers is increased. However, in a study by Nugraha [33] in Indonesia, he found that the headmaster did not recognize the work of teachers that caused the organizational climate and the work content of teachers to be negative. Thus, this also has an indirect detrimental impact on the school's performance and goals that should be considered by the headmasters. One of the respondents (TF:29/4) who said he was a little upset:

\begin{abstract}
"Recognizing the work of teachers can help inspire and keep teachers happier. However, this is not going to happen to some of us. The administrators are mean to those of us and have always left us unrecognize. I say, as a representative, that they should be fair to everyone with equal opportunities without prejudice. I assume that the administrator who establishes a positive relationship with all teachers will make the working experience more rewarding, helping to boost teacher success and student achievement."
\end{abstract}

Based on the interviewed result and the quantitative survey data, it appears that there is not so much difference between the two methodologies. This is due to the fact that the questions raised for interviews were based on the previous findings of the literature review. The findings show that the job satisfaction of the teacher is linked to the organizational climate. It seems that the teachers in this study have little difficulty, both because they are happy with the work and because of the organizational environment. Teachers would have been so pleased in this study, because the headmaster recognized their hard work in teaching, which increased their job satisfaction. However, if the headmaster did not recognize the work of the teachers that created a negative organizational climate and job satisfaction for the teachers. This also has an indirect harmful impact on the performance of the school and on the objectives to be considered by the headmasters.

One important contribution to this study is that the headmaster gave the teachers a chance to make decisions that made the teachers feel respected and recognized. Besides, the supervision for teachers is importance [34]. This means that the teachers involved in the study are directly involved in determining the direction and objectives of the school. The administration, in particular the headmaster, always gives teachers the opportunity to present their ideas on teaching and learning. This makes teachers feel valued and respected as experts in the climate of the organization. Every teacher has a chance to speak in the school administration. Each school decision will be evaluated and taken in conjunction with the teacher.

School administrators are the most important human resource in the management of the organization, and they also play a role in creating a harmonious climate for the satisfaction of their employees [13]. Organizational leaders must be responsible for creating a positive atmosphere and motivating their employees to do so [9]. These relations have a significant impact on the satisfaction of teachers at work.

More specifically, the results of this study will help administrators, educators and stakeholders to gain a deeper insight into vision creation and leaders focused on developing and promoting a better school environment. In addition, managers and policy makers should use the results of this study as a framework for the design and implementation of policies that will support different stakeholders and improve the performance of their teachers. Therefore, the educational consequences for teachers, headmaster/headmaster, school officials and educational staff should be borne in mind that emotional dissonance is correlated with high emotional fatigue, low organizational engagement and poor work satisfaction [11].

\title{
5. CONCLUSION
}

Teachers are more motivated to achieve the objectives of the school, when they are in agreement with the administration. This makes the school environment more positive and ultimately increase the satisfaction of teachers at work. This study adds to the knowledge of education management that has been established by exploring the link between the school's organizational environment and teacher job satisfaction with different reference primary school settings. Literature confirms that the organizational environment of good leadership will encourage and empower their followers with job satisfaction in work and development. 
This study has its own limitations that need to be identified in order to improve the job satisfaction and organizational climate of the school. The first limitation, potential teacher job satisfaction studies investigate how teachers can lower their emotional stress level. Although several factors influence job satisfaction, a large number of studies point to working conditions, particularly communication and decisionmaking by headmasters, as having an impact. Second limitation was only confined to 23 elementary schools in Alor Jangus, Kedah. The results obtained cannot be applied to other non-included primary schools. Eventually, junior participants may not feel able to share their views on the organizational environment because they do not want to risk their relationship with their seniors. Moreover, the connection between the school's environmental influences and teacher's specific characteristics is dynamic and the relationship's internal framework needs to be further explored.

\section{REFERENCES}

[1] H. Entoh and M. K. Abdullah, "The Influence of School Organizational Climate on Metacognition Awareness among Primary School Teachers in the North Island Zone of Sabah," Malaysian Journal of Social Sciences and Humanities, vol. 4, no. 1, pp. 60-73, 2019.

[2] W. N. Eh Tem, "The influence of organizational climate on teacher work performance in vocational colleges," Master Thesis, Universiti Tun Hussein Onn Malaysia, 2013.

[3] T.A. Judge, H.M. Weiss, J.D. Kammeyer-Mueller, and C.L. Hulin, "Job attitudes, job satisfaction, and job affect: A century of continuity and of change," J Appl Psychol, vol. 102, no. 3, pp. 356-374, 2017, doi: 10.1037/apl0000181.

[4] Ministry of Education, Malaysian Education Development Plan 2013-2025 (in Malay). Putrajaya: Ministry of Education, 2013

[5] N. Bai, R. Piri, and A. Piri, "Investigating school organizational climate and job satisfaction from Kalale physical education teachers' point of view," Research Journal of Sport Science, vol. 2, no. 2, pp. 45-49, 2014

[6] N. Kariming and A. S. Ambotang, "Relationship of school climate to job satisfaction of 6th grade East Coast Sabah teachers," (in Malay), Jurnal Komunikasi Borneo, vol. 6, pp. 53-64, 2018.

[7] E. L. Eng Fei and C. G. K. Han, "The Relationship of Principals' Leadership and School Climate with Teachers' Motivation," (in Malay) Malaysian Journal of Social Sciences and Humanities (MJSSH), vol. 3, no. 2, pp. 1-16, 2018.

[8] K. A. Aziz and F. Hussin, "Effect of organizational climate on job satisfaction of secondary school teachers in the Kuala Terengganu district," Proceeding of the ICECRS, 2016, vol. 1, no. 1, pp. 49-58, doi: 10.21070/picecrs.v1i1.575.

[9] A. V. Valdez, A. P. Guro, H. Norhana, N. H. Cana, and L. M. Lawi, "School organizational climate and job satisfaction of MSU junior high school teachers," International Journal of Science and Management Studies (IJSMS), vol. 2, no. 1, pp. 92-99, 2019.

[10] M. R. Zamani and F. Karim, "Relationship between spiritual intelligence and job satisfaction among female high school teachers," Educational Research and Reviews, vol. 10, no. 6, pp. 739-743, 2015.

[11] G. Maiti, "Relationship between primary teachers' job satisfaction and their organizational climate in Kharagpur-i, district Paschim Medinipur," Indian Journal of Applied Research, vol. 9, no. 11, pp. 19-20, 2019.

[12] M. Mukhtar, "Role of Organizational Climate in Managing Job Satisfaction among Academic Staff: Empirical Evidence from Education Sector of Pakistan," Int J Adv Res Manage Comput Sci, vol. 1, no. 1, pp. 1-6, 2020.

[13] S.C. Wynn, "What research says about leadership styles and their implications for school climate and teacher job satisfaction," Master of Education Applied Research Projects, 2019.

[14] N. Hassan and J. A. Wahab, "Job satisfaction among teachers in Bangsar zone secondary schools," (in Malay), Seminar Pendidikan Serantau Ke-VIII, 2017, pp. 401-408.

[15] F. L. Hamdan, "The influence of organizational climate on job satisfaction among the Poly-tech Mara College (KPTM) lecturers]," (in Malay), e-Proceeding of the 4th Global Summit on Education, vol. 4, no. 3, 2016, pp. 304-313.

[16] R. Kapa and B. Gimbert, "Job satisfaction, school rule enforcement and teacher victimization," School Effectiveness and School Improvement, vol. 29, no. 1, pp. 150-168, 2017, doi: 10.1080/09243453.2017.1395747.

[17] S. N. Amedome, "The influence of leadership on school climate: A case of senior high schools in Hohoe Municipality of Ghana," Academy of Educational Leadership Journal, vol. 22, no. 2, 2018.

[18] H. Hardianto, "Optimization of teacher job satisfaction," (in Bahasa), Jurnal Manajemen Pendidikan, vol. 5, no. 2, pp. 190-195, 2019, doi: 10.24246/j.jk.2018.v5.i2.p190-195.

[19] I. A. G. Azmi and N. R. Siren, "Job satisfaction level of non-government Islamic religious school teachers," Akademika, vol. 88, no. 2, pp. 35-58, 2018.

[20] R. Krejcie and D.W. Morgan, "Determining sample size for research activities," Educational and Psychological Measurement, vol. 30, pp. 607-610, 1970.

[21] B. Johnson, J. Stevens, and K. Zvoch, "Teachers' perceptions of school climate: A validity study of scores from the Revised School Level Environment Questionnaire," Educational and Psychological Measurement, vol. 67, pp. 833-844, 2007, doi: 10.1177/0013164406299102.

[22] P. E. Lester, "Development and factor analysis of the teacher job satisfaction questionnaire (TJSQ)," Educational and Psychological Measurement, vol. 47, no. 1, pp. 223-233, 1987. 
[23] E.A. Locke, "What is job satisfaction?" Organizational Behavior and Human Performance, vol. 4, no. 4, pp. 309-336, 1969.

[24] D. Van Maele and M. Van Houtte, "The role of teacher and faculty trust in forming teachers' job satisfaction: Do years of experience make a difference?" Teaching and Teacher Education, vol. 28, no. 6, pp. 879-889, 2012, doi: 10.1016/j.tate.2012.04.001.

[25] C. B. Stewart. and R. Robles-Piña, "Black and blue: The impact of nonfatal teacher victimization," The Journal of At-Risk Issues, vol. 14, no. 2, 9-15, 2008.

[26] I. G. Katsantonis, "Investigation of the Impact of School Climate and Teachers' Self-Efficacy on Job Satisfaction: A Cross-Cultural Approach," European Journal of Investigation in Health Psychology Education, vol. 10, pp. 119-133, 2019.

[27] N. A. Wahab and M. Y. Abdullah, "The relationship of the style of leadership and management of the headmistress with the job satisfaction of the Johor state religious school teachers," (in Malay), Jurnal Ilmi, vol. 8, no. 1, pp. 136-150, 2018.

[28] A. Adeniji, H. Falola, and O. Salau, "A modelling relationship between work satisfaction and faculty performance in the Nigerian private universities," Scientific Journal of Kurdistan University of Medical Sciences, vol. 10, no. 32, pp. 63-80, 2014.

[29] A. Saboor, M. Rehman, and S. Rehman, "Organizational justice and employee contextual performance: the moderating effect of organizational respect," Pakistan Business Review, vol. 19, no. 4, pp. 995-1011, 2018.

[30] A. Saboor, M. Ilyas, and S. Rehman, "Linking empowerment and capability development with innovative behavior: testing a moderating model of employee's creative self-efficacy," Pakistan Business Review, vol. 19, no. 1, pp. 176-194, 2017.

[31] W. Anjilus and R. Talip, "Impact of organizational climate on job satisfaction of academic teachers in sixth-grade centers," (in Malay), Malaysian Journal of Social Sciences and Humanities, vol. 3, no. 4, pp. 35-49, 2019.

[32] N. U. Mutiara and A. Sobandi, "School climate as a determinant of student learning," (in Bahasa), Jurnal Pendidikan Manajemen Perkantoran, vol. 3, no. 1, pp. 218-225, 2018.

[33] M. F. Nugraha, "Iklim organisasi dan kepuasan kerja guru di sekolah Singosari Delitua"/Organizational climate and job satisfaction at Singosari Delitua school, Jurnal Diversita, vol. 5, no. 1, pp. 19-23, 2019, doi: 10.17509/jpm.v3i1.9458.

[34] M. D. Kasa, et al., "The morale of supervision: The impact of technical supervision skills of teaching and learning on teachers' self-efficacy," International Journal of Criminology and Sociology, vol. 9, pp. 335-349, 2020. 